\title{
Other Post Employment Benefits-The Other Elephant in the Room
}

\author{
Catherine Plante
}

Department of Accounting and Finance, University of New Hampshire, United States

\begin{abstract}
The governments of the fifty states of the United States have made promises to past and present employees regarding retirement benefits-predominately pensions and healthcare coverage. The issues surrounding the pension obligations made to these employees have been well examined but the obligations due to promises of healthcare coverage have not received as much attention. There is great variance among the OPEB liability reported by the states. This study examines reasons for the variance. The future payment of healthcare obligations, like pensions, will put extreme stress on states in the future if the impact of these promises is not understood now. Understanding the influence healthcare assumptions have on the reported liabilitites is an important step to understanding these liabilities.
\end{abstract}

Keywords: Post-Employment Benefits (OPEB), Great Variance Among, Retirement Benefits, Comprehensive Annual Financial Reports (CAFRs)

\section{INTRODUCTION}

In 2004, GASB 45 Accounting and Financial Reporting by Employers for Post-Employment Benefits Other Than Pensions required state and local governments to report their non-pension PostEmployment Benefits (OPEB) as liabilities on their financial statements starting after December, 2006. These liabilities are dominated by healthcare benefits granted to retirees. Up until this point, state and local governments reported the cost of these benefits on a "pay as you go" basis. GASB 45 required governments, for the first time, to report the value of healthcare promises made to retirees. The purpose of this study is to examine the OPEB liabilities reported by the states. The OPEB liabilities vary widely among the states; this study examines potential causes for the variance. States reported a total of over $\$ 638$ billion in OPEB liabilities in 2009 (PCT, 2011). It is important that the numbers reported by the states are accurate and reliable so good decisions regarding funding and future benefits can be made.

\subsection{Why OPEBS are Important}

During 2009, states reported an average OPEB liability of over $\$ 9$ billion and growing. According to
PricewaterhouseCoopers, the rate of healthcare inflation in 2008 has been close to $10 \%$ and shows no signs of slowing down (PWC, 2008). Changes in the healthcare laws have added uncertainty to the future of healthcare in the United States. States are examining the retirement benefits promised to their employees to determine if changes are necessary. The recent upheaval in Wisconsin shows how important benefits are to state workers and how difficult it is to change them.

Public attention has focused on the status of states' unfunded pensions. During 2009, a $\$ 660$ billion gap between pension liabilities and pension assets existed (PCT, 2011). Less widely discussed is the funding concerns caused by OPEBS. At the current time, funding for OPEBs is not required which means there is great potential for the gap between obligations to retirees and the ability to pay for them to widen. In fact, in 2009, only $\$ 31$ billion had been contributed towards the $\$ 638$ billion in OPEB liability (PCT, 2011). For some states, the future financial burden for OPEBs will be minimal; for example, Nebraska does not offer retirees healthcare benefits. For other states these large, unfunded liabilities will become a greater problem in the future. For example, New York has over $\$ 56$ billion in OPEB liabilities, none of which are funded. The requirements for governments to report 
OPEB liabilities may provide a wake-up call to many states to the financial burden the retirement benefits promised to past and present employees will cause to future generations.

This study examines the OPEB liabilities reported by state governments in order to understand differences in the liability among the states and underlying causes for the differences. The magnitude of these liabilities and the financial stresses on the states makes it imperative that the reported numbers for the OPEB liabilities are accurate and reliable. As more and more states are faced with crucial decisions about the ability to pay current and future commitments while examining if and how commitments to their employees should be changed, an understanding of how the numbers are calculated and how assumptions affect the calculations is necessary for good decision making.

\section{MATERIALS AND METHODS}

\subsection{Data}

The 2009 Comprehensive Annual Financial Reports (CAFRs) of the 50 states are examined to determine the OPEB assumptions made when calculating the OPEB liability. Not all states report information regarding their OPEB in their CAFR. For example, Nebraska does not report OPEB information because they do not offer an OPEB plan. Thus Nebraska is not included in the sample. Other states do not report their OPEB data either because they are multi-employer plans and currently are not required to report the numbers or they created an independent trust fund that issues its own financial statements. Requests for information were made to any state's OPEB plan that did not report actuarial assumptions in their CAFR. Four states (Arizona, New Jersey, Oklahoma and South Carolina) did not respond and therefore are not included in the sample. Forty-five states are included in the sample.

Of the forty-five states examined, the reported OPEB liability varies widely from the $\$ 67$ million reported by South Dakota to the $\$ 69$ billion reported by California. However, these numbers may be misleading. States with large numbers of potential retirees will have larger liabilities because a larger number of people are receiving coverage. The variable potential retirees is calculated as the number of state employees who are currently retired plus the number of current full time employees which represents the number of people covered by the plan. Using the total number of past and present employees to scale the OPEB liability will allow a better comparison between states by controlling for size. The importance of scaling is exhibited in Table 1.

\subsection{Variables}

In 2009, variations among the OPEB liabilities per potential retiree reported by the states are large. This study examines the potential sources of the variation by examining five factors. The first factor is the liability itself and the underlying assumptions used to calculate the liability. The second factor examined is economies of scale. The third factor is the states' ability to pay while the fourth factor is the cost of healthcare faced by the individual states. The fifth factor is the level of benefits provided by the states to their employees. By examining these five factors, a better understanding of the variation in the reported liabilities and the underlying factors related to the liability should be achieved.

The first factor examined is the OPEB liability itself. Like pensions, the OPEB liability is based on actuarial assumptions. Two major assumptions used for both pensions and OPEB calculations are the discount rate and return on investment assumption. These two assumptions often are the same. Thirty-eight of the fortyfive states reported a discount rate/return on investment rate. Of these thirty-eight, thirty-three assumed a rate between $4-5 \%$. There is very little variance among the states regarding these assumptions. Since only thirtyeight states report this assumption and because there is little variance among the states regarding this assumption, it is not included in the analysis to preserve sample size (Including these assumptions in the analysis did not affect the results).

What makes the OPEB liability unique from the pension liability is the third assumption-healthcare inflation rate. The healthcare inflation rate assumption is the rate the state assumes healthcare costs are going to increase by in the future (no state assumes a decrease in costs) when calculating their OPEB liability. This healthcare inflation rate assumption is particularly interesting because there is little guidance as to how to determine the value. GASB 45 says that it should be partially based on past experience but the emphasis should be on long term future trends. This emphasis on "crystal ball gazing" makes the healthcare assumption particularly interesting to examine during these times of turbulence in the healthcare industry. States with higher assumed rates of healthcare cost increases should have higher liabilities. In fact, as Keating and Berman (2007) found, the assumptions made regarding healthcare inflation rates are a cost driver to the reported liability. The rate assumed by the states varies widely. The 
healthcare inflation rate assumed by the states in 2009 varies from a rate of $6 \%$, assumed by West Virginia to a rate of $13.6 \%$ assumed by Idaho. Some may question whether the healthcare rate assumed is important. Corporations, under FASB 106, have to report the impact of a $1 \%$ increase in the assumption on the reported OPEB liability. Looking at the 50 largest US corporations that provide healthcare to their retirees in 2009 , a $1 \%$ increase in the healthcare assumptions corresponds to a $\$ 215$ million increase in the liability. This analysis may be understating the importance of the healthcare assumption because the $\$ 215$ million is based on an average OPEB liability of $\$ 3.4$ billion for corporations while the states included in the sample have an average of $\$ 9.1$ billion in OPEB liability. Thus, the potential to overstate or understate the OPEB liability is great. All 45 states included in the sample reported their assumed rate of increase for future healthcare costs. It is expected that the healthcare assumption assumed by the states should be positively related to the OPEB liability per potential retiree.

Table 1. OPEB liabilities by state

\begin{tabular}{|c|c|c|c|c|c|}
\hline & \multicolumn{3}{|c|}{------------2009 OPEB liability------------- } & \multicolumn{2}{|c|}{----------2009 OPEB liab/potential retiree--------- } \\
\hline 1 & California & $\$ 69,351,300,000$ & 1 & Connecticut & $\$ 226,999$ \\
\hline 2 & New York & $\$ 56,286,000,000$ & 2 & Alaska & $\$ 194,766$ \\
\hline 3 & Texas & $\$ 53,890,544.000$ & 3 & Delaware & $\$ 135,230$ \\
\hline 4 & Thiois & $\$ 43,949,729,000$ & 4 & Iiiionis & $\$ 134,436$ \\
\hline 5 & Ohio & $\$ 43,360,893,000$ & 5 & Michigan & $\$ 132,705$ \\
\hline 6 & Michigan & $\$ 41,419,600,000$ & 6 & Hawaii & $\$ 126,685$ \\
\hline 7 & North Carolina & $\$ 33,814,515,000$ & 7 & North Carolina & $\$ 194,786$ \\
\hline 8 & Connecticut & $\$ 20,284,637,000$ & 8 & West Virginia & $\$ 135,230$ \\
\hline 9 & Georgin & $\$ 17,407,621,000$ & 9 & Georgia & $\$ 134,436$ \\
\hline 10 & Alaska & $\$ 16,098,602,000$ & 10 & Ohio & $\$ 132,705$ \\
\hline 11 & Pennsylcvania & $\$ 15,166,300,000$ & 11 & New Hampshire & $\$ 126,685$ \\
\hline 12 & Maryland & $\$ 14,919,073,000$ & 12 & Texas & $\$ 118,786$ \\
\hline 13 & Massachusetts & $\$ 11,512,100,000$ & 13 & Maryland & $\$ 99,525$ \\
\hline 14 & Alabama & $\$ 10,791,300,000$ & 14 & Alabama & $\$ 98,906$ \\
\hline 15 & Louisiana & $\$ 8,754,555,000$ & 15 & Masschusetts & $\$ 98,864$ \\
\hline 16 & Hawaii & $\$ 7,618,372,000$ & 16 & New York & $\$ 98,276$ \\
\hline 17 & Kentucky & $\$ 6,362,640,000$ & 17 & Vermont & $\$ 95,352$ \\
\hline 18 & Wahington & $\$ 5,830,000,000$ & 18 & Califormia & $\$ 94,795$ \\
\hline 19 & West Virginia & $\$ 5,636,000,000$ & 19 & Louisiana & $\$ 92,128$ \\
\hline 20 & Delaware & $\$ 3,742,846,000$ & 20 & Maine & $\$ 85,582$ \\
\hline 21 & Florida & $\$ 3,321,637,000$ & 21 & Kentucky & $\$ 85,510$ \\
\hline 22 & Missouri & $\$ 3,226,105,000$ & 22 & Pennsylvania & $\$ 72,394$ \\
\hline 23 & New Hampshire & $\$ 3,116,916,000$ & 23 & New Mexico & $\$ 69,349$ \\
\hline 24 & New Mexico & $\$ 2,625,963,000$ & 24 & Nevada & $\$ 60,414$ \\
\hline 25 & Maine & $\$ 2,326,834,000$ & 25 & Washington & $\$ 54,125$ \\
\hline 26 & Wisconsin & $\$ 2,043,914,000$ & 26 & Virginia & $\$ 53,694$ \\
\hline 27 & Colorado & $\$ 1,874,005,000$ & 27 & Rhode island & $\$ 43,280$ \\
\hline 28 & Nevada & $\$ 1,865,879,000$ & 28 & Missouri & $\$ 36,715$ \\
\hline 29 & Arkansas & $\$ 1,136,601,000$ & 29 & Arkansas & $\$ 36,665$ \\
\hline 30 & Tennessee & $\$ 1,865,809,000$ & 30 & Colorado & $\$ 27,489$ \\
\hline 31 & Vermont & $\$ 1,746,879,000$ & 31 & Wisconsin & $\$ 22,021$ \\
\hline 32 & Minnesota & $\$ 1,628,934,000$ & 32 & Montana & $\$ 19,515$ \\
\hline 33 & Phode island & $\$ 1,136,601,000$ & 33 & Idaho & $\$ 17,478$ \\
\hline 34 & Mississppi & $\$ 788,189,000$ & 34 & Tennsessee & $\$ 14,563$ \\
\hline 35 & Oregon & $\$ 727,711,000$ & 35 & Florida & $\$ 12,520$ \\
\hline 36 & Montana & $\$ 555,047,000$ & 36 & Mississippi & $\$ 11,335$ \\
\hline 37 & Lowa & $\$ 540,894,000$ & 37 & Utah & $\$ 11,146$ \\
\hline 38 & Indiana & $\$ 538,200,000$ & 38 & North Dakot & $\$ 10,123$ \\
\hline 39 & Idaho & $\$ 524,859,000$ & 39 & Wyoring & $\$ 6,645$ \\
\hline 40 & Utah & $\$ 493,746,000$ & 40 & Mnnesota & $\$ 6,395$ \\
\hline 41 & Kansas & $\$ 480,752,000$ & 41 & Lowa & $\$ 6,222$ \\
\hline 42 & Wyoming & $\$ 236,910,000$ & 42 & Oregon & $\$ 6,214$ \\
\hline 43 & North Dakota & $\$ 174,161,000$ & 43 & Idiana & $\$ 4,536$ \\
\hline 44 & South Dakota & $\$ 161,376,000$ & 44 & Kansas & $\$ 2,488$ \\
\hline 45 & South Dakota & $\$ 67,100,000$ & 45 & South Dakota & $\$ 2,379$ \\
\hline
\end{tabular}


An economy of scale is the second factor that may explain the differences in the liability per potential retiree reported among the states. The number of potential retirees in the state may indicate economies of scale exist with states with more employees having a benefit over states with fewer employees. Taking this idea one step further-the number of potential retirees per population may also indicate whether economies of scale exist within the state employees' healthcare plans. The percentage of people that are employed by the state measures whether states employ a larger number of workers relative to the state's overall population or whether they run leaner operations. States with a higher percentage of state employees may enjoy economies of scale because of their political clout. If a larger proportion of the state's population works for the state, for example, that may give the states' benefit officers greater power to negotiate better terms for their healthcare plans. The two variables, states' potential retirees and the percent of the state's population that are potential retirees, should be negatively related to the cost per person if the states are enjoying economies of scale. Additionally, because 2009 was a recession year and therefore may skew the number of state employees, the percent change in the number of state employees from 2005-2009 is also included as a control variable. No prediction as to sign for this variable is made.

The third factor that may explain the differences in the reported liabilities among the states may be the differences in their ability to pay for healthcare for their retirees. Poorer states may have to offer more barebones plans than states with more resources. The ability of a state to pay for healthcare is measured using several variables. The first variable is the per capita income of the state's population. The assumption is that richer taxpayers lead to higher taxes thereby giving states greater ability to offer more generous plans than states with poorer taxpayers that may require more government services. Per capita income is expected to be positively related to the liability per potential retiree. The second variable is the amount that the state's revenue exceeded the state's expenditures in 2007 divided by the state's population. This "net income per person" indicates the resources available to the state to pay healthcare fees. States that keep expenses lower than revenues have more financial flexibility and thus may be able to provide more healthcare to their employees. "Net income per person" is expected to be positively related to the liability per potential retiree. The third variable is the unfunded pension liability per potential retiree. If the states are unwilling or unable to fund their pensions, they may be unwilling or unable to offer more healthcare coverage to their employees and/or require the employees to cover more of their insurance premiums which decreases their liabilities. This variable should be negatively related to the OPEB liability. The fourth variable is the state's contributions toward their OPEB liability in 2009. Theoretically, states with higher liabilities should be contributing more towards them. If a state has the resources to fund their obligations, they may be more likely to grant their employees higher benefits. It is predicted that contributions will be positively related to the liability.

The fourth factor that may explain the differences among the states' liabilities is the cost of healthcare itself. Some parts of the country may have higher healthcare costs than other parts. Looking at a state's expenditures on healthcare may be related to state employee healthcare costs faced by the states but may also reflect the generosity of the state in paying healthcare costs for the poor and the elderly of their states. The purpose of this study is to explain the differences in reported healthcare liabilities for public employees and retirees and not how much states are expending on healthcare for all. The state's healthcare expenditures cannot be broken into employees' expenditures and overall expenditures. Therefore, to proxy for the differences in the cost of providing healthcare to state employees among the states, a variable "insurance premiums" is used. This variable is the average cost in each state of purchasing healthcare insurance for family coverage in the year 2009. This variable reflects differences in healthcare costs among states. If healthcare costs are higher in New York, the premium for healthcare insurance should be higher. This variable proxies for differences in healthcare costs among the states and should be positively related to the OPEB liability.

The fifth factor is differences in healthcare liabilities may exist because of differences in the benefits given to retirees. States that provide more generous healthcare plans should have higher healthcare liabilities than states that provide more modest coverage. To measure the amount of the healthcare benefits provided to state employees, the percentage of the government employees that are covered by a collective bargaining agreement is used. It is assumed that the more unionized the employees are, the better the benefits they will receive. Historically, unionization and better benefits have been related (Buchmueller et al., 2002). Although many states are currently negotiating with their public unions 
to trim pensions and benefits, it is assumed that unions still have a positive impact on the amount of healthcare insurance provided. Therefore, states with higher union representation should have higher healthcare liabilities per potential retiree because they offer more generous plans.

To further explore differences in coverage provided, the amount of pension liability per potential retiree is also included in the model. It is assumed that states with generous pension plans will offer generous healthcare plans. Both the percent of potential retirees covered under a collective bargaining agreement and the pension liability per potential retiree should be positively related to the OPEB liability. Descriptive statistics for the variables discussed above, their sources and their expected sign are reported in Table 2.
As shown in Table 2, there is a wide variation in most variables. This table indicates there is little consistency among the states with regards to how much they owe in OPEB liabilities, the assumptions made which are the basis of these liabilities and to the amount they contribute towards the healthcare liabilities.

To examine what factors influence a state's reported OPEB liability, the following regression is used:

OPEB/potential retiree $=$ healthcare assumption + potential retiree+ potential retiree /population $+\%$ change in \# employees + per capita income + "net income" / population + unfunded pension/potential retiree + contributions/potential retiree + premium costs + percent unionized + pension liability/potential retiree.

Table 2. Descriptive statistics

\begin{tabular}{|c|c|c|c|c|c|}
\hline Variable & Expected sign mean & Mean & Std Dev. & Min & Max \\
\hline Open liab/ potential retirees & + & $\$ 57,673$ & $\$ 54,964$ & $\$ 2,379$ & $\$ 226,999$ \\
\hline Healthcare assumption & - & 0.0923 & 0.015 & 0.06 & 0.136 \\
\hline Potential retirees & - & 183,503 & 188,025 & 22,501 & $1,000,038$ \\
\hline Potential retirees /population & & 0.035 & 0.017 & 0.019 & 0.128 \\
\hline Percent change employees & & 0.0526 & 0.045 & -0.027 & 0.0143 \\
\hline Per capita income & + & $\$ 37,632$ & $\$ 7,452$ & $\$ 3,229$ & $\$ 54,397$ \\
\hline Net income/population & + & $\$ 1,384$ & $\$ 7,840$ & $\$ 243$ & $\$ 5,436$ \\
\hline Unfunded pension retirees & - & $\$ 70,814$ & $\$ 44,243$ & $\$ 2,230$ & $\$ 5,436$ \\
\hline Contribution/potential retirees & + & $\$ 1,624$ & $\$ 1,633$ & $\$-$ & $\$ 6,816$ \\
\hline Premium costs & + & $\$ 12,896$ & $\$ 928$ & $\$ 10,969$ & $\$ 14,723$ \\
\hline Unionization & + & $38 \%$ & $18 \%$ & $11 \%$ & $73 \%$ \\
\hline Pension liability potential retirees & + & $\$ 298,167$ & $\$ 97,346$ & $\$ 171,719$ & $\$ 648,543$ \\
\hline Number of state employees & \multicolumn{5}{|c|}{ Full-time employees -2009 annual survey of public employment and payroll-U.S census bureau } \\
\hline Number of retirees & \multicolumn{5}{|c|}{ Number of state employees retirees 2001-2002-U.S census bureau } \\
\hline OPEB liability & \multicolumn{5}{|c|}{ OPEB liability for 2009-PEW center on the states-the widening gap April 2011} \\
\hline Health care assumption & \multicolumn{5}{|c|}{ Individual state's 2009 CAFRs } \\
\hline Population & \multicolumn{5}{|c|}{2009 resident population by state U.S census bureau } \\
\hline Percentage of change in employees & \multicolumn{5}{|c|}{ Full time employees -2005 annual survey of public employees and payroll U.S census bureau } \\
\hline Per capita income & \multicolumn{5}{|c|}{ Per capita personal income by state for 2009 -U.S census bureau } \\
\hline State revenues & \multicolumn{5}{|c|}{ Total revenue by state 2007 U.S. census bureau } \\
\hline Unfunded pension & \multicolumn{5}{|c|}{ Dollar amount of the state pension that is unfunded is 2009 -PEW center on the states the widening gap April 2011} \\
\hline Contributions & \multicolumn{5}{|c|}{2009 contributions made by the states towards their OPEB-REW center on the states the widening gap April 2011} \\
\hline Percent unionized & \multicolumn{5}{|c|}{ Percent of public employees covered by a collective bargaining agreement 2010 current population survey } \\
\hline Pension liability & \multicolumn{5}{|c|}{2009 total pension liability for state employees -REW center on the state the widening gap April 2011} \\
\hline
\end{tabular}

Table 3. Regression results

\begin{tabular}{lrrrl}
\hline & Coefficients & \multicolumn{1}{c}{ Standard error } & \multicolumn{1}{c}{ S Stat } & P-value \\
\hline Intercept & -50058.466010000 & 75638.957690000 & -0.661807983 & 0.5126894710 \\
Health assump 2009 & -886045.592800000 & 299850.387500000 & -2.954958972 & 0.0057317910 \\
Potential retirees & 0.045862346 & 0.023996770 & 1.911188315 & 0.0646986760 \\
\#Emp+ret/pop & 192185.842500000 & 565621.693700000 & 0.339778061 & 0.7361768460 \\
Percentage of Change & 143512.689300000 & 98016.970930000 & 1.464161644 & 0.1526117090 \\
Per capita income & 0.485695639 & 0.665241276 & 0.730104485 & 0.4704778670 \\
Net income per capita & -9.917287242 & 9.185804774 & -1.079631833 & 0.2881340880 \\
Unfunded pen/emp+ret & 0.342123436 & 0.108568916 & 3.151209853 & 0.0034485060 \\
Contrib/employee+ret & 24.186699650 & 3.033630074 & 7.972857290 & $3.3869 \mathrm{E}-09000$ \\
Premium costs & 10.393861090 & 5.277396993 & 1.969505251 & 0.0573373130 \\
Percent unionized & 39.474047150 & 251.288133600 & 0.157086793 & 0.8761336320 \\
Pen liab/emp+ret & -0.123307890 & 0.061610156 & -2.001421631 & 0.0536254472 \\
\hline R & & &
\end{tabular}


Where:

$\begin{aligned} & \text { Potential retirees }= \begin{array}{l}\text { Number of state } \\ \text { employees }+ \text { number of } \\ \text { state retirees }\end{array} \\ & \text { Percent change in number } \\ & \text { of state employees from } \\ & 2005-2009 \\ & \text { change in employees }\end{aligned}$

Net income $/$ population $=\begin{aligned} & (\text { State revenue-state } \\ & \text { expenditures }) / \text { population }\end{aligned}$

The results are presented in Table 3 .

\section{RESULTS AND DISCUSSION}

The results indicate that six of the variables examined are significantly related to the OPEB liability yet not always in the direction expected. The first factor examined is the OEPB liability itself. The healthcare inflation rate assumed is significant but not in the predicted direction. Mathematically, the higher the assumed healthcare inflation rate, the higher the liability but the results show that governments with high liabilities per potential retiree are assuming lower healthcare costs. The wide range in predicted healthcare inflation rates (6-13\%) indicate either there is a wide variance in state's ability to control future healthcare costs or that states are having difficulty in determining what healthcare costs are going to do in the future. It may also indicate that governments with higher healthcare assumptions maybe over estimating their healthcare liabilities which builds slack into their reported numbers. States with lower assumptions may be underreporting their liabilities. It would behoove state legislatures to examine the assumptions that underlie the reported liability to understand how the reported liability is dependent upon the underlying assumptions and verify that the assumptions represent economic reality.

The second factor examined is economies of scale. The results indicate that states do not enjoy economies of scale when reporting healthcare liabilities. States with a larger number of potential retirees face a higher OPEB liability per potential retiree. No evidence of economies of scales exists when negotiating healthcare costs; in fact, the results indicate the opposite. These results indicate that the political clout of large numbers of covered employees ensure better benefits to the employees themselves rather than cost savings for the state.

The third factor examined is the states' ability to pay. It is predicted that states with higher per capital income and higher "net income per capita" will offer better healthcare plans causing higher liabilities per potential retiree. The model also predicts that states with large unfunded pension liabilities will have lower healthcare liabilities per potential retiree. The results show that neither the wealth of the state's taxpayers as measured by per capita income nor the state's fiscal restraint as measured by "net income per capita" influence the level of liabilities reported. However, the results are significant regarding unfunded pensions per potential employee. It was assumed that states with difficulties funding pension plans would not have the ability to finance large OPEB liabilities. Instead, the results indicate that states that don't fund their pensions also incur large liabilities for healthcare. It seems that states with pension problems also have problems with large OPEB liabilities. However, contribution per potential retire is positively related to the liability per potential retiree. In 2009 , states with higher liabilities per potential retiree contributed more towards their OPEB liabilities. These results indicate that governments who promise a lot of healthcare benefits are trying to fund the liabilities. States with large, unfunded pension liabilities seem to be trying to avoid the same mistakes with these newly reported healthcare liabilities.

The fourth factor examined is the cost of healthcare faced by the states. The results show premium costs are positively related to the reported liability. The cost of insurance premiums is used to proxy for the cost of healthcare in the state. States with higher premiums and thus higher healthcare costs have higher liabilities per potential retirees. These results are logical and consistent.

The fifth factor examined is the level of benefits provided to total potential retirees. Information on the level of benefits provided to employees is not available on a state by states basis. Therefore, the percentage of the workforce that operates under a collective bargaining agreement and the pension liability per potential retiree proxy for the level of healthcare benefits offered to retirees. Unionization is not significantly related to the liability while pension liability is negatively related. These results indicate that unionization does not impact the level of healthcare benefits given. However, the results indicate that states with more generous pension plans have less generous healthcare plans. It is possible that states are trading off pension benefits with healthcare benefits when providing retirement coverage to employees. The results may also indicate that it is easier to change healthcare coverage through increased co-pays than it is to change pension plans. 
In summary, states with higher healthcare liabilities per potential retiree contribute more to their healthcare liabilities and assume lower rates of increases in healthcare costs. They have a larger number of potential retirees and lower pension liabilities but these pension liabilities are more likely to be underfunded. These states also face higher costs for the healthcare coverage they provide.

\section{CONCLUSION}

This study finds that several factors influence the OPEB liability per potential retiree. States that cover a larger number of employees have higher liabilities per potential retiree. The large number of state employees, past and present, appears to be using their political clout to accrue better healthcare benefits for themselves rather than the states accruing the benefits of large numbers through lower costs per person. Next, states with high pension liabilities per person have lower healthcare liabilities per person while states with high unfunded pension liabilities per person have higher healthcare liabilities per person. These results indicate two different things. Firstly, it appears that states make tradeoffs. States that offer generous pension plans offer less generous healthcare plans. However, states that have problems with their pension plans because they are underfunded appear to be compensating by offering more healthcare coverage. All these results are interesting but further analysis is necessary. The states are currently in a time of flux regarding their retirement benefits. Examining these results again in a few years will be intriguing to see what changes have been made to state retirement benefits.

One of the most important contributions of this study is the examination of the assumed healthcare inflation rate. So far, no other study has examined this assumption as made by the states. The relationship between actuarial assumptions and pension liabilities has been studied but little research has looked at the relationship between actuarial assumptions and the liability reported for the cost of providing healthcare to retirees. Recall the estimates ranged from $6 \%$ to over $13 \%$ in 2009 . This wide range of estimates calls into question whether the OPEB liabilities currently being reported by the states represents the "true" costs of these liabilities. When examining the fiscal health of the states, it is important to accurately measure the obligations the states have made to their employees. Retirees' healthcare costs are another "hidden" liability that has only recently appeared on state and local government's financial statements. It is possible that the wide range in healthcare assumptions accurately reflect the underlying liability. It is also possible that the wide range in assumptions reflect the newness in reporting the OPEB liability and the difficulty in predicting future healthcare costs. Either way, users of the states' financial statements should be aware of the variance among the states when making predictions as to future healthcare costs and the impact these predictions have on the reported numbers.

\section{REFERENCES}

Buchmueller, T.C., J. DiNardo and R.G. Valletta, 2002. Union effects on health insurance provision and coverage in the united states. Industrial Labor Relations Rev., 55: 610-627.

Keating, E.K. and E.S. Berman, 2007. Unfunded public employee health care benefits and GASB No. 45. Account. Horiz., 21: 245-263. DOI: 10.2308/acch.2007.21.3.245

PCT, 2011. The widening gap: The great Recession's impact on state pension and retiree health care costs. The Pew Charitable Trusts.

PWC, 2008. Health Research Institute. PricewaterhouseCoopers LLP. 